\title{
Universiti Malaysia PAHANG

\section{An implementation of differential evolution algorithm for a single product and single period multi-echelon supply chain network model}

Ayda Emdadian¹, S. G. Ponnambalam²*, G. Kanagaraj ${ }^{3+}$

\begin{tabular}{|c|c|}
\hline $\begin{array}{l}\text { *Correspondence } \\
\text { sgponnambalam@ump.edu.my } \\
\text { +This author contributes } \\
\text { equally to this work } \\
\\
{ }^{1} \text { School of Engineering } \\
\text { Monash University Malaysia } \\
46150 \text { Bandar Sunway, } \\
\text { Selangor, Malaysia } \\
\text { ayda1369e@yahoo.com } \\
\text { 2 Faculty of Manufacturing } \\
\text { Engineering,University } \\
\text { Malaysia Pahang,26600 } \\
\text { Pekan, Pahang, Malaysia } \\
\text { 3Department of Mechatronics } \\
\text { Engineering, Thiagarajar } \\
\text { College of Engineering, } \\
\text { Madurai, India } \\
\text { gkmech@tce.edu }\end{array}$ & $\begin{array}{l}\text { ABSTRACT } \\
\text { In this paper, five variants of Differential Evolution (DE) algorithms are proposed to solve } \\
\text { the multi-echelon supply chain network optimization problem. Supply chain network } \\
\text { composed of different stages which involves products, services and information flow } \\
\text { between suppliers and customers, is a value-added chain that provides customers products } \\
\text { with the quickest delivery and the most competitive price. Hence, there is a need to optimize } \\
\text { the supply chain by finding the optimum configuration of the network in order to get a good } \\
\text { compromise between several objectives. The supply chain problem utilized in this study is } \\
\text { taken from literature which incorporates demand, capacity, raw-material availability, and } \\
\text { sequencing constraints in order to maximize total profitability. The performance of DE } \\
\text { variants has been investigated by solving three stage multi-echelon supply chain network } \\
\text { optimization problems for twenty demand scenarios with each supply chain settings. The }\end{array}$ \\
\hline $\begin{array}{l}\text { Articles Info: } \\
\text { Received } \mathbf{1 1} \text { June } \mathbf{2 0 1 8} \\
\text { Received in revised form } \\
7 \text { August } 2018 \\
\text { Accepted } \mathbf{1 1} \text { Sept } \mathbf{2 0 1 8} \\
\text { Available Online } \mathbf{1 3} \text { Sept } \\
\mathbf{2 0 1 8}\end{array}$ & $\begin{array}{l}\text { objective is to find the optimal alignment of procurement, production, and distribution while } \\
\text { aiming towards maximizing profit. The results show that the proposed DE algorithm is able } \\
\text { to achieve better performance on a set of supply chain problem with different scenarios } \\
\text { those obtained by well-known classical GA and PSO. }\end{array}$ \\
\hline $\begin{array}{l}\text { Keywords: } \\
\text { Multi-echelon supply } \\
\text { chain architecture } \\
\text { Evolutionary approach } \\
\text { Differential Evolution } \\
\text { algorithms } \\
\text { Swarm intelligence }\end{array}$ & \\
\hline
\end{tabular}

\section{INTRODUCTION}

In today's global competition in manufacturing and distribution, the successes of an industry are depended on cost-effective supply chain management under various markets, logistics and production uncertainties. Uncertainties in the supply chain usually decrease profit, i.e. increase total supply chain cost [1]. The key issues in supply chain management can broadly be divided into main categories: (i) supply chain design (ii) supply chain planning and (iii) supply chain control. In a supply chain, the flow of goods between a supplier and customer passes through several stages, and each stage may consist of many 
facilities thus making it difficult to manage its whole integration. One of these critical decisions may involve integrating the supply chain in which the companies participate to enable the ability to make business decisions jointly. These strategic decisions lead to costly, time-consuming investment as the facilities located today, are expected to remain in operation for a long time. Hence, it is very important to design an efficient supply chain to facilitate the movements of goods to increase the competitiveness introduced by the market globalization [2].

A supply chain network (SCN) typically comprised of suppliers, producers, distributors, and customers. SCN establish the distribution channels, and the number of materials and items to consume, produce, and ship from suppliers to customers. The SCN design problem is one of the most comprehensive strategic decision problems that need to be optimized for long-term efficient operation of a whole supply chain. It determines the number, location, capacity and type of plants, warehouses, and distribution centers to be used. These problems typically increase as the number of supply chain layers increase, the time period increases, and the number of products and purchase orders increase. These cause the network search space and time required to obtain a solution to increase markedly. Therefore, the SCN design problem is an NPcomplete problem [3]. According to the findings of Ebikake et al [4], finding the best solution for supply chain management is NP-hard problem, so it must be strategically dealt with, on a case to case basis developing an efficient methodology that can find out the optimal or near-optimal solution in minimum computational time. It is intractable to solve this kind of problem in the real world as it often incurs expensive computational efforts.

Meta-heuristics are kind of near-optimal algorithms that were proposed in the two recent decades to integrate basic heuristic methods in higher-level structures in order to effectively and efficiently search a solution space. Nowadays, these algorithms have a large number of applications in an optimization of different hard-to-solve problems. In this paper, we use DE variants for solving constrained multi-echelon supply chain network problems of Kadadevaramath [1]. The performance of the DE variants used in this paper has been compared with genetic algorithm and particle swarm optimization algorithm. The results indicated that the DE method can obtain a better quality solution compared to classical GA and PSO.

Rest of the paper is organized as follows. Section 2 deals with the work that is done previously in the related field. Section 3 explains problem description and mathematical formulation of three stage multiechelon supply chain network model. The implementation of DE algorithm is given in section 4 followed by numerical illustration given in section 5 . The results are given in section 6 and finally, conclusions are given in section 7 .

\section{LITERATURE REVIEW}

A large amount of literature on supply management places great emphasis on the integration of different components of the chain. Most of the research in this area is based on the classic work of Clark and Scarf [5-6] more discussion of two-echelon models may be found in [7]. Bora and Grossmann [8] formulated the problem as a multistage stochastic program with decision dependent elements where investment strategies are considered to reduce uncertainty, and time-varying distributions are used to describe uncertainty and proposed a new mixed-integer/disjunctive programming model.

Cohen and Moon [9] extend Cohen and Lee [10] developed a constrained optimization model; called PILOT, to investigate the effects of various parameters on supply chain cost, and consider the additional problem of determining which manufacturing facilities and distribution centers should be open. The objective function of the PILOT model is a cost function, consisting of fixed and variable production and transportation costs, subject to supply, capacity, assignment, demand, and raw material requirement constraints. Based on the results of their example supply chain system, the authors conclude that there are a number of factors that may dominate supply chain costs under a variety of situations and that transportation costs play a significant role in the overall costs of supply chain operations.

Goh et al [11] focused on the operational issues of a Two-echelon Single-Vendor-Multiple-Buyers Supply chain problem under vendor managed inventory mode of operation and proposed PSO and hybrid GA to solve this problem. Che [12] developed a decision methodology for the production and distribution planning of a multi-echelon unbalanced supply chain problem. He proposed a mathematical model to determine the best pattern of the supply chain system by integrating cost and time criteria and simultaneously considering multiple products, production loss, transportation loss, quantity discount, production capacity, and starting-operation quantity.

Ishii et al. [13] develop a deterministic model for determining the base stock levels and lead times associated with the lowest cost solution for an integrated supply chain on a finite horizon. The stock levels and lead times are determined in such a way as to prevent stock out, and to minimize the amount of 
obsolete ("dead") inventory at each stock point. Their model utilizes a pull-type ordering system, which is driven by, in this case, linear (and known) demand processes.

Pyke and Cohen [14] develop a mathematical programming model for an integrated supply chain, using stochastic sub-models to calculate the values of the included random variables included in the mathematical program. The authors consider a -level supply chain, consisting of one product, one manufacturing facility, one warehousing facility, and one retailer. The model minimizes total cost, subject to a service level constraint, and holds the setup times, processing times, and replenishment lead times constant. The model yields the approximate economic (minimum cost) reorder interval, replenishment batch sizes, and the order-up-to product levels (for the retailer) for a particular production network.

Work of Babu and Gujarathi [15] focused on solving three stage supply chain problems using multiobjective differential evolution (MODE) algorithm. In their study, three cases of objective functions were considered and Pareto-optimal solutions were obtained for each case. The results were compared with those reported using a non-dominated sorting genetic algorithm (NSGA-II) in the literature. Minimizing total cost has been the primitive objective in most of the SCN design models [16-17]. But for a supply chain, producing products at minimum cost is not the only objective, a satisfying customer is also equally important. Later some researchers started incorporating more than one competing objectives such as improving customer service and reducing cost in their models.

Many of the aforementioned articles use Lagrangian relaxations or heuristic methods to solve the model. Recently, Atamtürk et al. [18] have shown how to formulate different variants of the joint inventorylocation problems in a supply chain comprising of a distribution center and retailers as conic mixed-integer problems. Mehrdad et al [19] extend the work by providing a novel conic integer reformulation for a joint inventory-location problem in a four echelon supply chain. Nowadays, as the use of a computer is rapidly increasing, many evolutionary computation methods for solving optimization problems have been introduced. Probably, among them, Differential Evolution (DE) is the most well-known class of evolutionary algorithms. It has taken a lot of attention of researchers in the several years. In this paper, the performance of five DE variants are examined for solving constrained multi echelon supply chain network problems of Kadadevaramath [1].

\section{MATHEMATICAL MODEL FORMULATION FOR THREE STAGE SINGLE PRODUCT, SINGLE PERIOD SUPPLY CHAIN NETWORK}

This section develops a mathematical model to quantify the relationship among all the decision variables involved in three stage multi-echelon supply chain network. Problem description, the notations, assumptions, decision variables used in this formulation are given below.

\section{PROBLEM DESCRIPTION}

A three echelon two-stage supply chain network considered in this paper is as shown in Fig.1. The first level consists of three suppliers which are suppliers of raw materials to plants for the manufacturing of products. The second level consists of two plants where products are manufactured and shipped to distribution centers. The third level consists of six distribution centers where products are sold to retailers. A product is manufactured from three different components can be supplied from any supplier to any of two plants. Plants may produce any product limited by its production and delivery capacity or decided by its strategy for each product. The final products are shipped to distribution centers based on demands. For the given cost data set the problem is to find the optimal alignment of procurement, production, and distribution while aiming at maximizing profit throughout the supply chain.

Assumptions

- A single product (made up of three components) flows through the supply chain network

- Distribution centers face random customer demand and demand distribution is assumed to be uniform

- The Quantity of goods at any installation takes integer values

- Linear holding cost rates exist only for manufacturing plants in the supply chain

- Shortages are not permitted (no shortage cost)

- Transportation costs are directly proportional to the quantity shipped

- Manufacturing costs are directly proportional to the number of products produced

- All installations have a finite capacity 

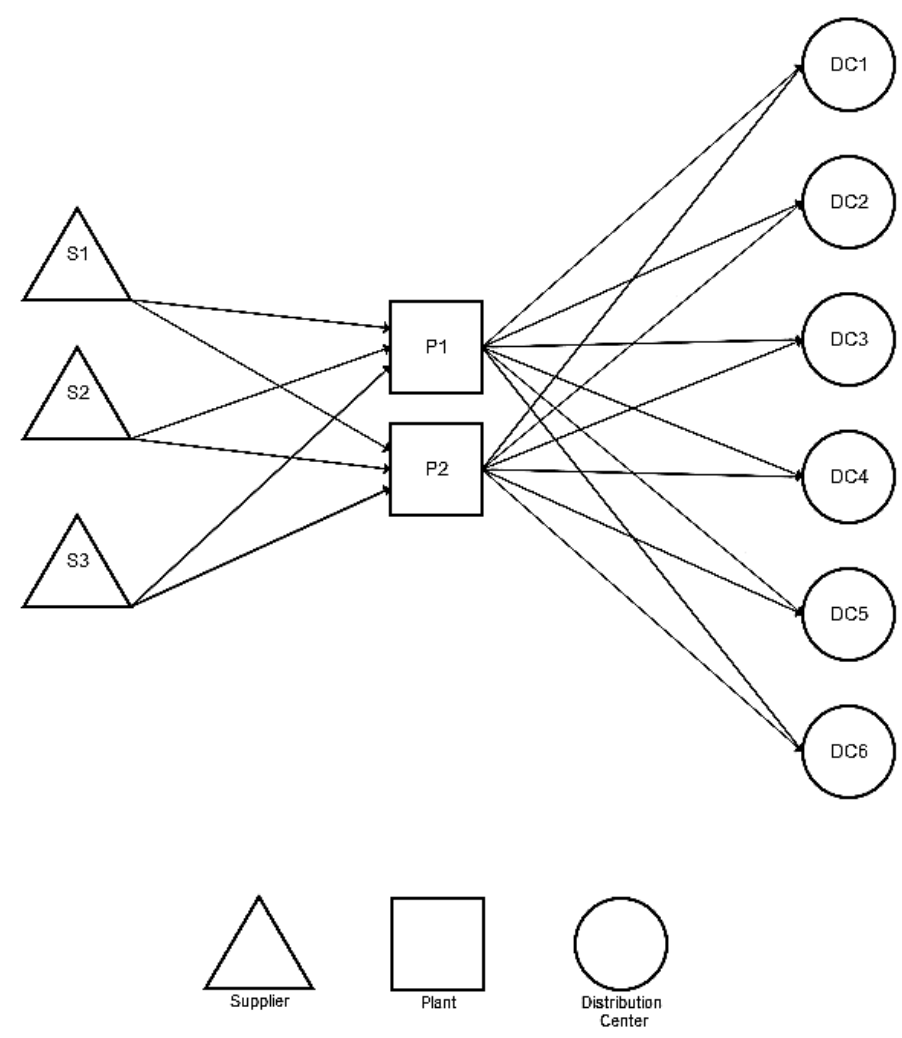

Figure 1. Three echelon supply chain network

Sets

Let $C$ be the set of components $c=1,2,3, \ldots \ldots . C$

Let $S$ be the set of suppliers $s=1,2,3, \ldots \ldots . S$

Let $P$ be the set of plants $p=1,2,3, \ldots \ldots . P$

Let $D$ be the set of distribution centers $d=1,2,3, \ldots \ldots . D$

\section{Parameters}

$L_{c, s} \quad$ be the capacity of supplier $s$ for component $c$

$C S_{c, s}$ be the cost of making a component $c$ by supplier $s$

$S T C_{c, s, p}$ be the transportation cost of a component $c$ from supplier $s$ to plant $p$ /unit

$U_{p} \quad$ be the capacity of plant $p$

$M C_{p}$ be the manufacturing cost of plant $p /$ unit

$I C_{p} \quad$ be the inventory cost at plant $p$ /unit/period

$P T C_{p . d}$ be the plant transportation cost from plant $p$ to distribution centre $d$

$D_{d} \quad$ be the demand at distribution centre $d$

$S P_{d} \quad$ be the selling price at distribution centre $d /$ unit

\section{Decision variables}

$X_{c, s, p} \quad$ be the amount of component shipped $c$ from supplier $s$ to plant $p$

$Y_{p, d} \quad$ be the amount of product shipped from plant $p$ to distribution centre $d$

\section{Mathematical model}

The objective function aims at maximizing the profit of overall supply chain distribution network which implies maximize the revenue and minimize the total supply chain cost

Maximize Profit $=$ Revenue - Total supply chain cost (TSCC)

Maximize Revenue $=\sum_{d}\left(D_{d} \times S P_{d}\right)$

Minimize TSCC $=$ TSMC + TMC + TTC 
Three components of total supply chain cost (TSCC) are:

(a)Total supplier material cost (TSMC) $=\sum_{c} \sum_{s} \sum_{p}(C S c, s \times X c, s, p)$

(b)Total manufacturing cost (TMC) $=\sum_{p}\left\{(M C p) \times\left(\sum_{d} Y p, d\right)\right\}+\sum_{p}\left\{(I C p) \times\left(\sum_{d} I c, p\right)\right\}$

(c)Total transport cost (TTC) $=\sum_{c} \sum_{s} \sum_{p}(X c, s, p \times S T C c, s, p)+\sum_{p} \sum_{d}(Y p, d \times P T C p, d)$

The objective function is given by

$$
\begin{gathered}
\text { Maximize Profit }=\sum_{d}\left(D_{d} \times S P_{d}\right)-\left\{\sum_{c} \sum_{s} \sum_{p}(C S c, s \times X c, s, p)+\sum_{p}\left\{(M C p) \times\left(\sum_{d} Y p, d\right)\right\}+\right. \\
\left.\sum_{p}\left\{(I C p) \times\left(\sum_{d} I c, p\right)\right\}+\sum_{c} \sum_{s} \sum_{p}(X c, s, p \times S T C c, s, p)+\sum_{p} \sum_{d}(Y p, d \times P T C p, d)\right\}
\end{gathered}
$$

Subject to

Supplier capacity constraint

$\sum_{P} X c, s, p \leq L c, s \quad \forall c, s$

Plant capacity constraint

$\sum_{P} Y p, d \leq U p \quad \forall p$

Demand constraint

$\sum_{P} Y p, d=D d \quad \forall d$

Inventory balancing constraint

$\sum_{v} X c, s, p-3 \sum_{d} Y p, d=0 \quad \forall c, s$

The objective function (1) maximizes the profit by minimizing the overall supply chain operating cost. Constraint (2) ensures that the total amount of any of the three components shipped from a supplier cannot exceed the supplier's capacity for that component. Constraint (3) specifies that the total production quantities do not exceed plant capacities individually. Constraint (4) ensures the products shifted from plant to distribution centers should be more than or equal to the demand raised by the distribution centers. Constraint (5) ensures that the components moved from the suppliers should be more than the products to be manufactured to meet the required demand.

\section{IMPLEMENTATION OF DIFFERENTIAL ALGORITHM}

Differential evolution (DE) was first proposed by Storn and Price in 1995 [20] as a powerful heuristic method for solving non-linear, non-differentiable and multimodal optimization problems. This technique has been structured based upon a combination of simple arithmetic operators, the classical crossover, mutation, and selection operators. In this method, the purpose of mutation and crossover is to generate new vectors, and the vectors will survive to the next generation are determined upon selection operator [21].

The theoretical framework of DE is very simple and DE is computationally inexpensive in terms of memory requirements and CPU times. Thus, nowadays, DE has gained much attention and wide application in a variety of fields [22-23]. Due to its simplicity, easy implementation, fast convergence, and robustness, the programming and operation of DE are also quite easy because it requires the settings of only three control parameters: population size, scaling factor, and crossover constant rate in crossover operator. These advantages facilitate the wide usage of DE. DE is a population-based search technique which utilizes NP variables as a population of D dimensional parameter vectors for each generation. Four main steps are involved in DE known as, initialization, mutation, recombination, and selection. DE produces an initial population by randomly sampling several points (each point is called a target vector) from the search space.

$$
\vec{x}_{i, 0}=\left(x_{i, 1,0}, x_{i, 2,0}, \ldots \ldots, x_{i, D, 0}\right), \quad i=1,2, \ldots \ldots, N P
$$

Where NP denotes the population size and D denotes the number of variables. At each generation $G$, a mutant vector $\left.\underset{v_{i, 0}}{x_{i, 1, G}}, v_{i, 2, G}, \ldots \ldots, v_{i, D, G}\right)(i \in 1,2, \ldots \ldots, N P)$ is produced by the mutation operator for each target vector $\underset{x}{\rightarrow_{i, G}}$. Afterward, the crossover operator is implemented on the mutant vector and the target vector to generate a trial vector $\vec{u}_{i, G}=\left(u_{i, 1, G}, u_{i, 2, G}, \ldots \ldots, u_{i, D, G}\right)(i \in 1,2, \ldots \ldots, N P)$. The crossover operator and the mutation operator together are called a trial vector generation strategy. In the selection phase, the function value of the trial vector is compared to the function value of the target vector and the target vector for the next generation is updated using equation (11). If the resulting vector yields a lower objective function value than a predetermined population member, the newly generated vector replaces 
the vector with which it was compared. In addition, the best parameter vector is evaluated for every generation in order to keep track of the progress that is made during the optimization process.

The DE algorithm adopted in this paper is presented below,

Initialize variable: $N P=30, D=30, F=0.5, C_{R}=0.9, g=1000$

Initialize randomly generated population of Np target vector $\left(X_{i g}\right)$, each with length $D$

While $g \leq 1000$

// Mutation operation to generate donor vector $\left(V_{i g}\right)$ based on random selected target vector for $i=1$ to $N P$

//Select different mutation relations depending upon the variant. For Example, DE/Rand/E is included in this algorithm.

Randomly choose 3 distinct vectors $X_{r 1, g}, X_{r 2, g}, X_{r 3, g}$

$V_{i, g}=X_{i p, g}+F^{*}\left(X_{i q, g}-X_{i r, g}\right)$

end

// Crossover operation to generate trial vectors $\left(y_{i, k}^{j}\right)$, consisting of both target and donor elements

for $i=1$ to $\mathrm{Np}$

Generate a randomly distributed number $R_{i}(0,1)$

for $j=1$ to $D$

$$
\begin{aligned}
& \text { if } R_{i} \leq C_{R} \\
& y_{i, k}^{j}=V_{i, j, g} \\
& \text { else } \\
& y_{i, k}^{j}=X_{i, j, g} \\
& \text { end }
\end{aligned}
$$

end

end

// Evaluation of target and trial vectors

// Selection operation to detect target vector for next generation $\left(X_{i, g+1}\right)$

for $i=1$ to $\mathrm{Np}$

end

$$
\begin{aligned}
& \text { if } f\left(y_{i, k}^{j}\right)>f\left(X_{i, g}\right) \\
& X_{i, g+1}=y_{i, k}^{j} \\
& \text { else } \\
& X_{i, g+1}=X_{i, g}
\end{aligned}
$$

end

$g=g+1$

\section{Mutation operation}

The mutation operation is based on the difference of different individuals (solutions), to produce a mutant vector $\mathrm{V}_{\mathrm{i}, \mathrm{G}}$ with respect to each individual $\mathrm{X}_{\mathrm{i}, \mathrm{G}}$, in the current population. This main operation is founded on the differences between randomly sampled pairs of solutions in the population. For each target vector $\mathrm{X}_{\mathrm{i}, \mathrm{G}}$, $\mathrm{i}=1,2, \ldots, \mathrm{NP}$, a mutant vector $\mathrm{V}_{\mathrm{i}, \mathrm{G}}$ can be made by the following mutation operators. In all types, the scale factor $\mathrm{F}$ is a positive control parameter for scaling the difference vector. Mutation is carried out by the mutation scheme. For each vector xi at any time or generation g, three randomly chosen vectors $X_{p}, X_{q}$ and $X_{r}$, and then resulting donor vector generated by any one of the following mutation strategies.

Strategy 1: DE/Rand/1/Bin

Strategy 2: DE/Best/1/Bin

$$
V_{i}^{g+1}=X_{p}^{g}+F\left(X_{q}^{g}-X_{r}^{g}\right)
$$

$$
v_{i}^{g+1}=X_{\text {best }}^{g}+F\left(X_{q}^{g}-X_{r}^{g}\right)
$$

Strategy 3: DE/Rand-to-Best/1/bin

$$
V_{i}^{g+1}=X_{p}^{g}+F\left(X_{\text {best }}^{g}-X_{p}^{g}\right)+F\left(X_{q}^{g}-X_{r}^{g}\right)
$$

Strategy 4: DE/Rand/2/bin

$$
V_{i}^{g+1}=X_{p}^{g}+F\left(X_{q}^{g}-X_{r}^{g}\right)+F\left(X_{s}^{g}-X_{t}^{g}\right)
$$


Strategy 5: DE/Current-to-Best/1/bin.

$$
V_{i}^{g+1}=X_{p}^{g}+F\left(X_{\text {best }}^{g}-X_{p}^{g}\right)+F\left(X_{q}^{g}-X_{r}^{g}\right)
$$

Here, $\mathrm{F}$ is the scale factor used to scale differential vector. $\mathrm{X}$ best is the solution with the best fitness value in the current population.

\section{Crossover operation}

In order to increase the diversity of the perturbed parameter vectors, a crossover is introduced after the mutation operation. Crossover operation is employed to generate a temporary or trial vector by replacing certain parameters of the target vector by the corresponding parameters of a randomly generated donor vector. To get each individual's trial vector, $\mathrm{U}_{\mathrm{i}, \mathrm{G}+1}$, crossover operation is performed between each individual and its corresponding mutant vector. The crossover operator is applied to obtain the trial vector $y_{i, k}^{j}$ from $V_{i, g}$ and $X_{i, g}$. The crossover is defined by

$$
y_{i, k}^{j}=\left\{\begin{array}{c}
V_{i, g} \text { if } R^{j} \leq C_{R} \text { or } j=i \\
X_{i, g} \text { if } R^{j}>C_{R} \text { and } j \neq i
\end{array}\right.
$$

where $i$ is a randomly chosen integer in the seti, i.e., $i \in I=\{1,2, \ldots, \mathrm{D}\}$; the superscript $j$ represents the $j$-th component of respective vectors; $R^{j} \in(0,1)$, drawn randomly for each $j$. The ultimate aim of the crossover rule is to obtain the trial vector $y_{i, k}^{j}$ with components coming from the components of the target vector $X_{i, g}$ and the mutated vector $V_{i, g}$. This is ensured by introducing $C_{R}$ and the set $I$. Notice that for $C_{R}=1$ the trial vector $y_{i, k}^{j}$ is the replica of the donor vector $V_{i, g}$. The targeting process (mutation and crossover) continues until all members of $X_{i, g}$ are considered. $C_{R}$ assumed to be 0.9 .

\section{Selection operation}

The selection operator of DE adopts a one-to-one competition between the target vector $X_{i, g}$ and the trial vector_ $U_{i, g}$. If the objective function value of the trial vector is less than or equal to that of the target vector, then the trial vector will survive into the next generation, otherwise, the target vector will enter the next generation: To generate the new individual for the next generation, selection operation is performed based on equation (12) between each individual and its corresponding trial vector.

$$
X_{i, g+1}=\left\{\begin{array}{l}
y_{i, k}^{j}, \text { if } f\left(y_{i, k}^{j}\right)>f\left(X_{i, g}\right) \\
X_{i, g}, \text { if } f\left(y_{i, k}^{j}\right) \leq f\left(X_{i, g}\right)
\end{array}\right.
$$

\section{Termination criteria}

DE algorithm will give the final objective value after the number of iteration has been chosen for a problem. In this study, the number of iteration assumed as 1000 generation and results published in the next section are based on 1000 generation.

\section{NUMERICAL ILLUSTRATION}

The DE starts the search by generating a population of candidate solutions. In our implementation, this population is randomly generated according to uniform distributions. That is, the parameters (gene values) $R i$ is randomly generated according to uniform distributions $U\left[R_{\text {imin }}, R_{i m a x}\right]$ where $R_{\text {imin }}$ and $R_{\text {imax }}$ are the minimum and the maximum possible values of $R i$. In DE algorithm, a solution can be represented as a vector of decision variables. The number of vectors representing the SCN is called population size (NP). In this study, each vector consists of 30 variables in a population size of 30 .

Fig. 2 shows representation of a solution vector consists of two sets of decision variables $X_{\mathrm{cvp}}$ and $Y_{\mathrm{Pd}}$. $\mathrm{X}_{\mathrm{csp}}$ represents the number of component ' $c$ ' shipped from supplier 's' to plant ' $p$ ', and $Y_{P d}$ represent the number of product shipped from plant 'p' to distribution centre 'd'. For example, $X_{232}$ represent the number of component 2 shipped from supplier 3 to plant 2. 


\begin{tabular}{|c|c|c|c|c|c|c|c|c|c|c|c|c|c|c|c|c|c|}
\hline $\mathbf{X}_{111}$ & $\mathbf{X}_{112}$ & $\mathbf{X}_{121}$ & $\mathbf{X}_{122}$ & $\mathbf{X}_{131}$ & $\mathbf{X}_{132}$ & $X_{211}$ & $\mathbf{X}_{212}$ & $X_{221}$ & $X_{222}$ & $\mathbf{X}_{231}$ & $\mathbf{X}_{232}$ & $\mathbf{X}_{311}$ & $\mathbf{X}_{312}$ & $\mathbf{X}_{321}$ & $\mathbf{X}_{322}$ & $\mathbf{X}_{331}$ & $\mathbf{X}_{332}$ \\
\hline 137 & 47 & 75 & 72 & 73 & 65 & 115 & 19 & 36 & 82 & 114 & 83 & 126 & 160 & 42 & 20 & 113 & 4 \\
\hline
\end{tabular}

a) $\mathrm{Xcsp}$

- Product $\mathrm{P}_{1}$ to all DCs $\Longrightarrow$ Product $\mathrm{P}_{2}$ to all DCs $\Longrightarrow$

\begin{tabular}{|l|l|l|l|l|l|l|l|l|l|l|l|}
\hline $\mathbf{Y}_{11}$ & $\mathbf{Y}_{12}$ & $\mathbf{Y}_{13}$ & $\mathbf{Y}_{14}$ & $\mathbf{Y}_{15}$ & $\mathbf{Y}_{16}$ & $\mathbf{Y}_{21}$ & $\mathbf{Y}_{22}$ & $\mathbf{Y}_{23}$ & $\mathbf{Y}_{24}$ & $\mathbf{Y}_{25}$ & $\mathbf{Y}_{26}$ \\
\hline $\mathbf{3 9}$ & $\mathbf{6 8}$ & $\mathbf{3 2}$ & $\mathbf{2 9}$ & $\mathbf{5 5}$ & $\mathbf{6 2}$ & $\mathbf{4 3}$ & $\mathbf{3 0}$ & $\mathbf{2 3}$ & $\mathbf{2 8}$ & $\mathbf{3 4}$ & $\mathbf{2 6}$ \\
\hline
\end{tabular}

b) $\mathrm{Y}_{\mathrm{Pd}}$

Fig. 2 Vector representation in DE algorithm for multi stage SCN architecture

Step 1: Initialization

Assume a population of five vectors, which are generated randomly and provided in Table 1.

Table 1, Target vectors representing the initial population

\begin{tabular}{|c|c|c|c|c|c|c|c|c|c|c|c|c|c|c|c|c|c|c|c|c|c|c|c|c|c|c|c|c|c|}
\hline & & & & & & & & & & & & & & & & & & & & & & & & & & & & & \\
\hline 10 & & & & ר & 76 & & & & & & & & & 40 & 2 & & 5 & 78 & & & & & & & & & & & \\
\hline
\end{tabular}

Step 2: Mutation

Once the initial population is generated, mutation operation is done to generate donor vectors. As explained in section 4.1, five different mutations are used to have five variants of DE. Among the five variants, $\mathrm{DE} /$ Rand/1/Bin is performing better. Hence, this section explains the implementation of DE/Rand/1/Bin mutation strategy using equation 6.

First, randomly select three vectors from the population. For example, vectors corresponding to row 5, 1 and 3 are selected randomly from Table 1 and $\mathrm{F}$ is assumed as 0.5 . The selected vectors are given in Table 2 .

Table 2, Vectors undergo mutation

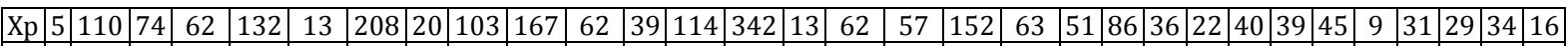

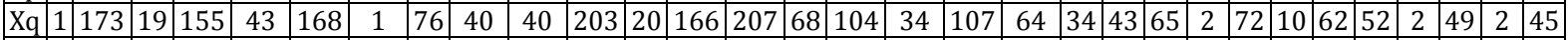

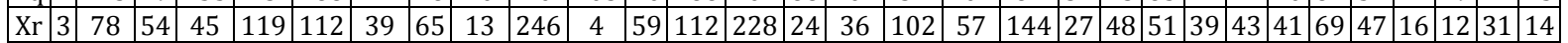

Table 3, Donor vector after mutation

\begin{tabular}{|l|l|l|l|l|l|l|l|l|l|l|l|l|l|l|l|l|l|l|l|l|l|l|l|l|l|l|l|l|l|}
\hline 157. & 56. & 11 & 9 & 4 & 18 & 25. & 116. & 6 & 161. & 19. & 14 & 331. & 3 & 9 & 2 & 17 & 2 & 54. & 83. & 4 & 3. & 54. & 23. & 41. & 11. & 2 & 47. & 19. & 31. \\
5 & 5 & 7 & 4 & 1 & 9 & 5 & 5 & 4 & 5 & 5 & 1 & 5 & 5 & 6 & 3 & 7 & 3 & 5 & 5 & 3 & 5 & 5 & 5 & 5 & 5 & 4 & 5 & 5 \\
\hline
\end{tabular}

Table 4, Corrected Donor vector

\begin{tabular}{|l|l|l|l|l|l|l|l|l|l|l|l|l|l|l|l|l|l|l|l|l|l|l|l|l|l|l|l|l|l|}
\hline 158 & 57 & 117 & 94 & 41 & 189 & 26 & 117 & 64 & 162 & 20 & 141 & 332 & 35 & 96 & 23 & 177 & 23 & 55 & 84 & 43 & 4 & 55 & 24 & 42 & 12 & 24 & 48 & 20 & 32 \\
\hline
\end{tabular}

The generated donor vector $\left(V_{i, g}\right)$ using DE/Rand/1/Bin mutation strategy is given in Table 3 . Since the vectors should only contain integer and positive values, each negative value should be replaced by absolute value and non-integer values should be replaced by integer using round function. The corrected donor vector is given in Table 4. 
Step 3: Crossover

A trial vector is generated using a crossover operator. The binominal crossover is used in this paper. In this stage, the trial vector $\left(y_{i, k}^{j}\right)$ is calculated by combining donor vector $\left(V_{i, g}\right)$ and target vector $\left(X_{i, g}\right)$ based on equation (11). $C_{R}$ represents the crossover probability. $\mathrm{R}$ is a random number between 0 and 1 , if $\mathrm{R}$ is smaller than $C_{R}$ the variable of mutation vector will be selected as a variable of the trial vector. Otherwise, the variable of a target vector will be selected as the variable of a trial vector. $C_{R}$ assumed to be 0.9 . For example, for the first position of trial vector; if $\mathrm{R}=0.1669$ the donor vector value, which is 158 copied into trail vector in the first position. For the second position of a trial vector; if $R=0.9351$, then target vector value, which is 19 copied into trail vector in the second position similar way the whole trial vectors are generated and are shown in Table 5.

\section{Table 5, Trial vector after crossover}

\begin{tabular}{|c|c|c|c|c|c|c|c|c|c|c|c|c|c|c|c|c|c|c|c|c|c|c|c|c|c|c|c|c|c|}
\hline 58 & 57 & & 94 & 41 & 39 & 26 & 17 & 64 & 162 & 0 & 41 & 32 & 35 & 96 & 23 & 177 & 23 & 55 & & 43 & 4 & 55 & 24 & 42 & 12 & 24 & 48 & 20 & \\
\hline 60 & 17 & 55 & 83 & 85 & 49 & 72 & 10 & & 67 & & 186 & 02 & 29 & 65 & 109 & 73 & 04 & 5 & & 50 & 38 & & & 91 & & & & & \\
\hline 26 & 71 & 44 & $2 ?$ & 2 & 61 & 40 & 91 & 74 & 107 & & 10 & 134 & 168 & 59 & $?$ & 124 & 105 & 90 & & & & & & & & & & & 2 \\
\hline 63 & 9 & & 70 & & 227 & 15 & 90 & 270 & 38 & & 7 & 353 & 8 & 28 & 91 & 127 & 103 & 48 & 89 & 29 & 41 & 26 & & & & & & & \\
\hline 42 & 134 & 82 & 71 & 100 & 73 & 90 & 15 & 250 & 149 & 80 & 44 & 10 & 201 & 67 & & 54 & 146 & \begin{tabular}{|l|}
70 \\
\end{tabular} & 17 & 82 & 6 & 40 & 14 & 27 & 79 & 15 & 57 & 34 & 42 \\
\hline
\end{tabular}

\section{Step 4: Selection}

At this stage, trial vector $\left(\mathrm{y}_{\mathrm{i}, \mathrm{k}}^{\mathrm{j}}\right)$, is compared with the target vector $\left(\mathrm{X}_{\mathrm{i}, \mathrm{g}}\right)$ to select vectors for the next generation. The selection will be done using equation (12), which is based on objective function value comparison. If the objective function value of a trial vector is better than the value of the target vector, the trial vector will be chosen as a new trial vector $\left(\mathrm{X}_{\mathrm{i}, \mathrm{g}+1}\right)$ for the next generation. Otherwise, the target vector will be chosen for the next generation. The target vectors for the next generation are shown in Table 6. The mutation, crossover, and selection operations are repeated until the termination condition is satisfied.

\section{Table 6, Target vectors for next generation}

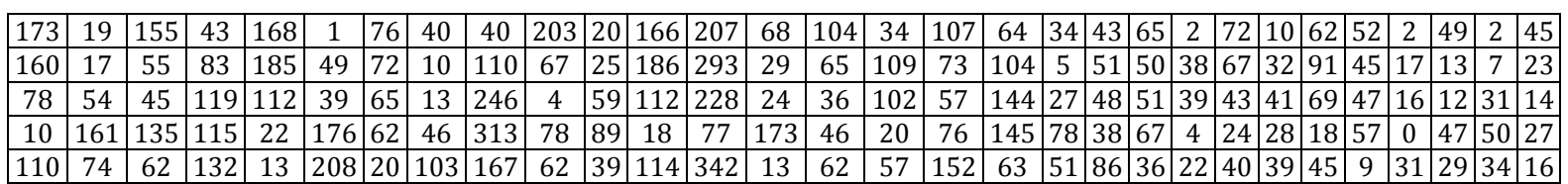

\section{RESULTS AND DISCUSSION}

The performance of the DE variants was evaluated by solving the supply chain problems considered by Kadadevaramath et al 2012. The DE parameters used in this paper are: number of generations $=1000$, number of vectors per population $=30$, mutation scale factor $=0.5$ and crossover rate $=0.9$. To assess the quality of five DE variants, a series of computational experiments were conducted. The computational experiments were done using a PC with Intel Core 2 Duo, 2.6 GHz and 3GB RAM under Mat lab environment.

For all twenty scenarios, demand rates followed the same as previous research for purpose of result comparison. All the twenty scenarios are considered to evaluate the performance of five DE variants. In order to compare the results of each variant with others, the same termination condition has been used which is based on the number of generation. 
Table 7 Optimal profit given by DE variants for all 20 scenarios

\begin{tabular}{cccccc}
\hline \multirow{2}{*}{ Scenario } & \multicolumn{5}{c}{ DE variants } \\
\cline { 2 - 5 } $\mathbf{1}$ & 693821 & 672086 & 676171 & 671019 & 675129 \\
$\mathbf{2}$ & 716444 & 707093 & 722314 & 694190 & 717853 \\
$\mathbf{3}$ & 682453 & 663375 & 675756 & 674255 & 681772 \\
$\mathbf{4}$ & 668867 & 649099 & 675036 & 657576 & 665509 \\
$\mathbf{5}$ & 650618 & 628437 & 643188 & 645505 & 640557 \\
$\mathbf{6}$ & 662956 & 641070 & 655714 & 657326 & 665230 \\
$\mathbf{7}$ & 675353 & 649113 & 663800 & 673513 & 667640 \\
$\mathbf{8}$ & 642256 & 629189 & 638198 & 636307 & 639562 \\
$\mathbf{9}$ & 644235 & 635217 & 638419 & 639312 & 639725 \\
$\mathbf{1 0}$ & 620780 & 584334 & 610262 & 614915 & 614153 \\
$\mathbf{1 1}$ & 618662 & 591943 & 612987 & 620885 & 617209 \\
$\mathbf{1 2}$ & 637072 & 604984 & 632456 & 629973 & 626318 \\
$\mathbf{1 3}$ & 693816 & 688345 & 683107 & 686424 & 689643 \\
$\mathbf{1 4}$ & 645156 & 630811 & 637692 & 633012 & 633621 \\
$\mathbf{1 5}$ & 679268 & 660562 & 678428 & 675553 & 674401 \\
$\mathbf{1 6}$ & 588173 & 579418 & 580990 & 583522 & 570255 \\
$\mathbf{1 7}$ & 598663 & 564032 & 588137 & 595366 & 583811 \\
$\mathbf{1 8}$ & 585288 & 564770 & 559161 & 583529 & 573938 \\
$\mathbf{1 9}$ & 581227 & 565709 & 577483 & 573947 & 561016 \\
$\mathbf{2 0}$ & 671595 & 657652 & 666832 & 662277 & 670745 \\
\hline
\end{tabular}

Table 8. Best Profit given by DE/Rand/1/Bin and GA Profit comparison

\begin{tabular}{ccccc}
\hline Scenario & DE/Rand/1/Bin profit & GA Profit & Difference & Percentage of improvement \\
\hline $\mathbf{1}$ & 693821 & 378179 & 315642 & 45.49 \\
$\mathbf{2}$ & 716444 & 423343 & 293101 & 40.91 \\
$\mathbf{3}$ & 682453 & 456036 & 226417 & 33.17 \\
$\mathbf{4}$ & 668867 & 368648 & 300219 & 44.88 \\
$\mathbf{5}$ & 650618 & 369655 & 280963 & 43.18 \\
$\mathbf{6}$ & 662956 & 349633 & 313323 & 47.26 \\
$\mathbf{7}$ & 675353 & 428033 & 247320 & 36.62 \\
$\mathbf{8}$ & 642256 & 345236 & 297020 & 46.24 \\
$\mathbf{9}$ & 644235 & 326946 & 317289 & 49.25 \\
$\mathbf{1 0}$ & 620780 & 310455 & 310325 & 49.98 \\
$\mathbf{1 1}$ & 618662 & 308154 & 310508 & 50.19 \\
$\mathbf{1 2}$ & 637072 & 321455 & 315617 & 49.54 \\
$\mathbf{1 3}$ & 693816 & 439865 & 253951 & 36.60 \\
$\mathbf{1 4}$ & 645156 & 302345 & 342811 & 53.13 \\
$\mathbf{1 5}$ & 679268 & 416633 & 262635 & 38.66 \\
$\mathbf{1 6}$ & 588173 & 294967 & 293206 & 49.85 \\
$\mathbf{1 7}$ & 598663 & 284643 & 314020 & 52.45 \\
$\mathbf{1 8}$ & 585288 & 301764 & 283524 & 48.44 \\
$\mathbf{1 9}$ & 581227 & 361047 & 220180 & 37.88 \\
$\mathbf{2 0}$ & 671595 & 374955 & 296640 & 44.16 \\
\hline
\end{tabular}

The performances of the DE variants are analyzed by the quality of the solution yielded and the computational effort required to obtain the best solution. The profit obtained after running each variant for 1000 generations are reported in Table 7 . The results clearly show that among the variants used in this study, the DE/Rand/1/bin gives the best performance within 1000 generations, which means the highest profit with lowest TSCC. 
Table 8-10 compares the best profit gave by DE/Rand/1/bin with GA, NLIWD-PSO best profits reported by Cardenas et al 2014 respectively. From Table 8-10 we observe that there is an improvement about $40 \%$ compared to GA and there is an improvement about $20 \%$ compared to NLIW-PSO and about $10 \%$ compared to optimal solution reported by [24]. Decision variables for best profit obtained by DE/Rand/1/bin variant for all 20 scenarios considered in this study are provided in Tables 11 . The optimal procurement of component1, component 2, component 3 from supplier 1, supplier 2, supplier 3, and optimal product manufacturing and distribution from plant 1 and plant 2 to all six distribution centers to satisfy the demand obtained by DE/Rand/1/bin variant for all 20 scenarios are listed in Table 12-14 respectively.

Table 9. Best Profit gave by DE/Rand/1/Bin and NLIWD-PSO Profit comparison

\begin{tabular}{ccccc}
\hline $\begin{array}{c}\text { Scenari } \\
\mathbf{0}\end{array}$ & $\begin{array}{c}\text { DE/Rand/1/Bin } \\
\text { profit }\end{array}$ & $\begin{array}{c}\text { NLIWD-PSO } \\
\text { Profit }\end{array}$ & $\begin{array}{c}\text { Differenc } \\
\text { e }\end{array}$ & $\begin{array}{c}\text { Percentage of } \\
\text { improvement }\end{array}$ \\
\hline $\mathbf{1}$ & 693821 & 549973 & 143848 & 20.73 \\
$\mathbf{2}$ & 716444 & 577768 & 138676 & 19.36 \\
$\mathbf{3}$ & 682453 & 547611 & 134842 & 19.76 \\
$\mathbf{4}$ & 668867 & 538945 & 129922 & 19.42 \\
$\mathbf{5}$ & 650618 & 519753 & 130865 & 20.11 \\
$\mathbf{6}$ & 662956 & 531895 & 131061 & 19.77 \\
$\mathbf{7}$ & 675353 & 540576 & 134777 & 19.96 \\
$\mathbf{8}$ & 642256 & 512192 & 130064 & 20.25 \\
$\mathbf{9}$ & 644235 & 518223 & 126012 & 19.56 \\
$\mathbf{1 0}$ & 620780 & 489435 & 131345 & 21.16 \\
$\mathbf{1 1}$ & 618662 & 491591 & 127071 & 21.12 \\
$\mathbf{1 2}$ & 637072 & 502506 & 134566 & 19.58 \\
$\mathbf{1 3}$ & 693816 & 557971 & 135845 & 20.58 \\
$\mathbf{1 4}$ & 645156 & 512355 & 132801 & 20.04 \\
$\mathbf{1 5}$ & 679268 & 543166 & 136102 & 21.39 \\
$\mathbf{1 6}$ & 588173 & 462378 & 125795 & 20.88 \\
$\mathbf{1 7}$ & 598663 & 473687 & 124976 & 21.19 \\
$\mathbf{1 8}$ & 585288 & 461293 & 123995 & 20.64 \\
$\mathbf{1 9}$ & 581227 & 461254 & 119973 & 20.21 \\
$\mathbf{2 0}$ & 671595 & 535868 & 135727 & \\
\hline
\end{tabular}

Table 10. Best Profit gave by DE/Rand/1/Bin and Optimal Profit comparison

\begin{tabular}{ccccc}
\hline Scenario & DE/Rand/1/Bin profit & Optimal Profit & Difference & Percentage of improvement \\
\hline $\mathbf{1}$ & 693821 & 617267 & 76554 & 11.03 \\
$\mathbf{2}$ & 716444 & 646013 & 70431 & 9.83 \\
$\mathbf{3}$ & 682453 & 613867 & 68586 & 10.05 \\
$\mathbf{4}$ & 668867 & 601763 & 67104 & 10.03 \\
$\mathbf{5}$ & 650618 & 583815 & 66803 & 10.27 \\
$\mathbf{6}$ & 662956 & 598785 & 64171 & 9.68 \\
$\mathbf{7}$ & 675353 & 610023 & 65330 & 9.67 \\
$\mathbf{8}$ & 642256 & 578901 & 63355 & 9.86 \\
$\mathbf{9}$ & 644235 & 582062 & 62173 & 9.65 \\
$\mathbf{1 0}$ & 620780 & 555707 & 65073 & 10.48 \\
$\mathbf{1 1}$ & 618662 & 560013 & 58649 & 9.48 \\
$\mathbf{1 2}$ & 637072 & 571454 & 65618 & 10.30 \\
$\mathbf{1 3}$ & 693816 & 625820 & 67996 & 9.80 \\
$\mathbf{1 4}$ & 645156 & 577047 & 68109 & 9.56 \\
$\mathbf{1 5}$ & 679268 & 613513 & 65755 & 10.08 \\
$\mathbf{1 6}$ & 588173 & 528866 & 59307 & 10.36 \\
$\mathbf{1 7}$ & 598663 & 536631 & 62032 & 10.05 \\
$\mathbf{1 8}$ & 585288 & 526438 & 58850 & 9.95 \\
$\mathbf{1 9}$ & 581227 & 523400 & 57827 & 10.17 \\
$\mathbf{2 0}$ & 671595 & 603272 & 68323 & \\
\hline
\end{tabular}


Table 11. Best values of Decision variables to the 20 scenarios given by DE/Rand/1/Bin

\begin{tabular}{|c|c|c|c|c|c|c|c|c|c|c|c|c|c|c|c|c|c|c|c|c|c|c|c|c|c|c|c|c|c|c|}
\hline & & & & & & & & & & & & & & & & & & & & & & & & & & & & & & \\
\hline enario & $x_{11}$ & $x_{1}$ & $x_{11}$ & $x_{12}$ & $X_{13}$ & $X_{13}$ & $X_{21}$ & $X_{212}$ & $X_{221}$ & $\mathrm{X}_{222}$ & $X_{231}$ & $X_{232}$ & $1 x_{2}$ & $X_{312}$ & $X_{321}$ & $X_{32}$ & $X_{331}$ & $X_{332}$ & $Y_{11}$ & $Y_{12}$ & $\mathrm{Y}_{13}$ & $Y_{14}$ & $\mathrm{Y}_{15}$ & $Y_{16}$ & $Y_{21}$ & $Y_{22}$ & $Y_{23}$ & & & $Y_{26}$ \\
\hline 1 & 3 & 8 & 4 & 5 & 2 & 13 & 42 & 64 & 347 & 2 & 176 & 38 & 222 & 139 & 120 & 17 & 185 & 65 & 60 & 96 & 22 & 28 & 71 & 88 & 23 & 2 & 33 & & $\overline{1 \varepsilon}$ & 2 \\
\hline 2 & 6 & 5 & 10 & 2 & 3 & 28 & 11 & 64 & 354 & 30 & 124 & 69 & 53 & 323 & 64 & 80 & 240 & 10 & 66 & \begin{tabular}{|l|}
36 \\
\end{tabular} & \begin{tabular}{|l|}
42 \\
\end{tabular} & \begin{tabular}{|l|}
53 \\
\end{tabular} & 67 & 19 & \begin{tabular}{|l|}
30 \\
\end{tabular} & 25 & \begin{tabular}{|l|}
18 \\
\end{tabular} & 28 & 25 & 77 \\
\hline 3 & 11 & 5 & 2 & 14 & 2 & 13 & 84 & 45 & 222 & 164 & 108 & 67 & 343 & 32 & 58 & 39 & 192 & 21 & 63 & \begin{tabular}{|l|}
28 \\
\end{tabular} & \begin{tabular}{|l|}
41 \\
\end{tabular} & 77 & \begin{tabular}{|l|}
41 \\
\end{tabular} & 82 & \begin{tabular}{|l|}
25 \\
\end{tabular} & \begin{tabular}{|l|}
42 \\
\end{tabular} & 13 & 5 & 35 & \\
\hline 4 & 7 & 1 & 4 & 1 & 13 & 28 & 38 & 56 & 328 & \begin{tabular}{|l|l}
47 \\
\end{tabular} & 77 & 127 & 281 & 56 & 81 & 18 & 195 & 21 & 58 & 58 & 62 & 73 & 52 & \begin{tabular}{|l|}
38 \\
\end{tabular} & 10 & 2 & 33 & 20 & 3 & 44 \\
\hline 5 & 17 & 0 & 4 & 7 & 9 & 33 & 101 & 36 & 191 & \begin{tabular}{|l|}
92 \\
\end{tabular} & 146 & 30 & 313 & 34 & 81 & 14 & 193 & 27 & 29 & \begin{tabular}{|l|}
53 \\
\end{tabular} & \begin{tabular}{|l|}
52 \\
\end{tabular} & 87 & \begin{tabular}{|l|}
52 \\
\end{tabular} & 78 & 35 & 26 & 11 & 11 & 4 & 4 \\
\hline 6 & 4 & 18 & 14 & 5 & 5 & 8 & 8 & 26 & 133 & 182 & 180 & 68 & 393 & 6 & 11 & 106 & 192 & 28 & 56 & \begin{tabular}{|l|}
89 \\
\end{tabular} & \begin{tabular}{|l|}
15 \\
\end{tabular} & \begin{tabular}{|l|}
73 \\
\end{tabular} & 44 & 32 & 5 & \begin{tabular}{|l|}
6 \\
\end{tabular} & \begin{tabular}{|l|}
41 \\
\end{tabular} & \begin{tabular}{l|l}
16 \\
\end{tabular} & 31 & 45 \\
\hline 7 & 6 & 18 & 5 & 13 & 1 & 2 & 74 & \begin{tabular}{|l|}
60 \\
\end{tabular} & 229 & 131 & 124 & 109 & 240 & 109 & 87 & 45 & 149 & 33 & 38 & 82 & \begin{tabular}{|l|}
19 \\
\end{tabular} & \begin{tabular}{|l|}
68 \\
\end{tabular} & 36 & 56 & 44 & 7 & \begin{tabular}{|l|}
71 \\
\end{tabular} & $\begin{array}{ll}3 & \end{array}$ & 20 & 26 \\
\hline 8 & 14 & 12 & 6 & 3 & 3 & 9 & 67 & 76 & 302 & 4 & 1111 & 19 & 127 & 151 & 120 & \begin{tabular}{|l|}
30 \\
\end{tabular} & 103 & \begin{tabular}{|l|}
133 \\
\end{tabular} & 45 & 71 & 61 & \begin{tabular}{|l|}
45 \\
\end{tabular} & 1 & 61 & 17 & 3 & 2 & 14 & \begin{tabular}{l|l}
97 & 1
\end{tabular} & 12 \\
\hline 9 & 10 & 19 & 1 & 15 & 8 & 16 & 87 & 22 & 144 & \begin{tabular}{|l|l}
38 \\
\end{tabular} & 92 & 119 & 391 & \begin{tabular}{|l|}
3 \\
\end{tabular} & 122 & \begin{tabular}{|l|l|}
10 \\
\end{tabular} & 107 & 142 & 68 & \begin{tabular}{|l|}
80 \\
\end{tabular} & \begin{tabular}{|l|}
43 \\
\end{tabular} & \begin{tabular}{|l|}
39 \\
\end{tabular} & 65 & 25 & 5 & 6 & 22 & \begin{tabular}{l|l}
39 \\
\end{tabular} & \begin{tabular}{l|l}
13 & 3 \\
\end{tabular} & 33 \\
\hline 10 & 2 & 7 & 1 & 2 & 5 & 0 & 67 & 64 & 307 & 13 & 21 & 81 & 293 & 98 & 139 & 3 & 107 & \begin{tabular}{|l|}
88 \\
\end{tabular} & 72 & \begin{tabular}{|l|}
44 \\
\end{tabular} & \begin{tabular}{|l|}
63 \\
\end{tabular} & 36 & 44 & 51 & 9 & 32 & 6 & \begin{tabular}{|l|l}
30 &
\end{tabular} & \begin{tabular}{l|l}
25 & \\
\end{tabular} & 7 \\
\hline 11 & 2 & 6 & 12 & 3 & 9 & 5 & 12 & 101 & 348 & \begin{tabular}{|l|l|}
48 \\
\end{tabular} & 133 & 73 & 208 & 28 & \begin{tabular}{|l|}
83 \\
\end{tabular} & 23 & 182 & \begin{tabular}{|l|}
25 \\
\end{tabular} & 71 & 35 & \begin{tabular}{|l|}
65 \\
\end{tabular} & 36 & \begin{tabular}{|l|}
50 \\
\end{tabular} & \begin{tabular}{|l|}
71 \\
\end{tabular} & 15 & \begin{tabular}{|l|}
23 \\
\end{tabular} & 28 & \begin{tabular}{l|l}
17 \\
\end{tabular} & 11 & 1 \\
\hline 12 & 10 & 7 & 5 & 2 & 3 & 6 & 71 & 1 & 198 & 1113 & 111 & 30 & 161 & 230 & \begin{tabular}{|l|}
88 \\
\end{tabular} & 50 & 170 & \begin{tabular}{|l|}
80 \\
\end{tabular} & 55 & 27 & 46 & \begin{tabular}{|l|}
45 \\
\end{tabular} & 60 & \begin{tabular}{|l|}
37 \\
\end{tabular} & 41 & \begin{tabular}{|c|}
68 \\
\end{tabular} & 21 & 6 & \begin{tabular}{l|l}
14 & 1 \\
\end{tabular} & 18 \\
\hline 13 & 2 & 1 & 6 & 7 & 8 & 57 & 88 & 46 & 217 & 149 & 115 & 41 & 350 & 8 & 42 & 94 & 178 & \begin{tabular}{|l|}
12 \\
\end{tabular} & 91 & 64 & \begin{tabular}{|l|}
61 \\
\end{tabular} & 12 & \begin{tabular}{|l|}
49 \\
\end{tabular} & 57 & \begin{tabular}{|l|}
0 \\
\end{tabular} & 12 & 11 & 57 & \begin{tabular}{l|l}
42 & 1 \\
\end{tabular} & 16 \\
\hline 14 & 5 & 1 & 1 & 3 & 3 & 1 & 23 & 104 & 225 & 1119 & 155 & 61 & 169 & 140 & 89 & 47 & 203 & 21 & 75 & 62 & 14 & 85 & 12 & \begin{tabular}{|l|}
43 \\
\end{tabular} & 15 & \begin{tabular}{|l|}
2 \\
\end{tabular} & 40 & 4 & 67 & 11 \\
\hline 15 & 2 & 24 & 1 & 8 & 3 & 9 & 62 & 29 & 150 & 196 & 28 & 159 & 334 & 44 & \begin{tabular}{|l|}
64 \\
\end{tabular} & 80 & 217 & \begin{tabular}{|l|}
13 \\
\end{tabular} & 78 & 64 & \begin{tabular}{|l|}
28 \\
\end{tabular} & 14 & \begin{tabular}{|l|}
9 \\
\end{tabular} & 87 & 2 & \begin{tabular}{|l|l}
8 \\
\end{tabular} & 33 & \begin{tabular}{l|l|}
71 \\
\end{tabular} & 62 & 9 \\
\hline 16 & 6 & 6 & 8 & 9 & 10 & 3 & 84 & 8 & 145 & 174 & 19 & 15 & 251 & 104 & 128 & 9 & 229 & 13 & 90 & 32 & \begin{tabular}{|l|}
29 \\
\end{tabular} & 44 & 48 & 46 & 1 & \begin{tabular}{|l|}
34 \\
\end{tabular} & 35 & \begin{tabular}{l|l}
25 \\
\end{tabular} & 6 & 10 \\
\hline 17 & 5 & 2 & 2 & 6 & 2 & 6 & 65 & 45 & 223 & \begin{tabular}{|l|}
13 \\
\end{tabular} & 62 & 63 & 240 & 143 & \begin{tabular}{|l|l} 
\\
\end{tabular} & 67 & 183 & 55 & 60 & \begin{tabular}{|l|}
75 \\
\end{tabular} & 43 & \begin{tabular}{|l|}
76 \\
\end{tabular} & 5 & \begin{tabular}{|l|}
19 \\
\end{tabular} & \begin{tabular}{|l|}
12 \\
\end{tabular} & 10 & \begin{tabular}{|l|}
10 \\
\end{tabular} & 1 & \begin{tabular}{l|l}
52 & 4 \\
\end{tabular} & 44 \\
\hline 18 & 6 & 16 & 6 & 1 & 6 & 7 & 16 & 26 & 321 & \begin{tabular}{|l|}
7 \\
\end{tabular} & 101 & 34 & 343 & 11 & 83 & 15 & \begin{tabular}{|l|}
19 \\
\end{tabular} & 197 & 42 & 78 & 49 & \begin{tabular}{|l|}
53 \\
\end{tabular} & 51 & 25 & 18 & 22 & 19 & 5 & \begin{tabular}{l|l}
11 & 2 \\
1
\end{tabular} & 27 \\
\hline 19 & 3 & 4 & 0 & 5 & 16 & 5 & 27 & 71 & \begin{tabular}{|l|}
96 \\
\end{tabular} & 63 & 186 & 50 & 264 & 36 & 28 & 97 & 172 & 55 & 62 & \begin{tabular}{|l|}
63 \\
\end{tabular} & \begin{tabular}{|l|}
15 \\
\end{tabular} & 31 & 38 & 55 & 20 & 4 & 43 & 25 & 34 & 2 \\
\hline 20 & 6 & 2 & 2 & 3 & 2 & 8 & 21 & 102 & 188 & 141 & 157 & 72 & 125 & 222 & 67 & 27 & 212 & \begin{tabular}{|l|}
8 \\
\end{tabular} & 48 & & 15 & 12 & 69 & & 33 & & \begin{tabular}{|l|}
80 \\
\end{tabular} & & \begin{tabular}{l|l}
12 \\
\end{tabular} & 7 \\
\hline
\end{tabular}

\begin{tabular}{|c|c|c|c|c|c|c|}
\hline Scenario & Plant1 supplier1 & Plant1 supplier2 & Plant1 supplier3 & Plant2 supplier1 & Plant2 supplier2 & Plant2 supplier3 \\
\hline 1 & 3 & 8 & 4 & 5 & 2 & 13 \\
\hline 2 & 6 & 5 & 10 & 2 & 3 & 28 \\
\hline 3 & 11 & 5 & 2 & 14 & 2 & 13 \\
\hline 4 & 7 & 1 & 4 & 1 & 13 & 28 \\
\hline 5 & 17 & 0 & 4 & 7 & 9 & 33 \\
\hline 6 & 4 & 18 & 14 & 5 & 5 & 8 \\
\hline 7 & 6 & 18 & 5 & 13 & 1 & 2 \\
\hline 8 & 14 & 12 & 6 & 3 & 3 & 9 \\
\hline 9 & 10 & 19 & 1 & 15 & 8 & 16 \\
\hline 10 & 2 & 7 & 1 & 2 & 5 & 0 \\
\hline 11 & 2 & 6 & 12 & 3 & 9 & 5 \\
\hline 12 & 10 & 7 & 5 & 2 & 3 & 6 \\
\hline 13 & 2 & 1 & 6 & 7 & 8 & 57 \\
\hline 14 & 5 & 1 & 1 & 3 & 3 & 1 \\
\hline 15 & 2 & 24 & 1 & 8 & 3 & 9 \\
\hline 16 & 6 & 6 & 8 & 9 & 10 & 3 \\
\hline 17 & 5 & 2 & 2 & 6 & 2 & 6 \\
\hline 18 & 6 & 16 & 6 & 1 & 6 & 7 \\
\hline 19 & 3 & 4 & 0 & 5 & 16 & 5 \\
\hline 20 & 6 & 2 & 2 & 3 & 2 & 8 \\
\hline
\end{tabular}

Table 13. Optimal procurement of component 2 from suppliers for DE/Rand/1/bin

\begin{tabular}{|c|c|c|c|c|c|c|}
\hline Scenario & $\begin{array}{c}\text { Plant1 } \\
\text { supplier1 }\end{array}$ & $\begin{array}{c}\text { Plant1 } \\
\text { supplier2 }\end{array}$ & $\begin{array}{c}\text { Plant1 } \\
\text { supplier3 }\end{array}$ & $\begin{array}{c}\text { Plant2 } \\
\text { supplier1 }\end{array}$ & $\begin{array}{c}\text { Plant2 } \\
\text { supplier2 }\end{array}$ & $\begin{array}{c}\text { Plant2 } \\
\text { supplier3 }\end{array}$ \\
\hline 1 & 42 & 64 & 347 & 2 & 176 & 38 \\
\hline 2 & 11 & 64 & 354 & 30 & 124 & 69 \\
\hline 3 & 84 & 45 & 222 & 164 & 108 & 67 \\
\hline 4 & 38 & 56 & 328 & 47 & 77 & 127 \\
\hline 5 & 101 & 36 & 191 & 92 & 146 & 30 \\
\hline 6 & 8 & 26 & 133 & 182 & 180 & 68 \\
\hline 7 & 74 & 60 & 229 & 131 & 124 & 109 \\
\hline 8 & 67 & 76 & 302 & 4 & 111 & 19 \\
\hline 9 & 87 & 22 & 144 & 38 & 92 & 119 \\
\hline 10 & 67 & 64 & 307 & 13 & 21 & 81 \\
\hline 11 & 12 & 101 & 348 & 48 & 133 & 73 \\
\hline 12 & 71 & 1 & 198 & 113 & 111 & 30 \\
\hline 13 & 88 & 46 & 217 & 149 & 115 & 41 \\
\hline 14 & 23 & 104 & 225 & 119 & 155 & 61 \\
\hline 15 & 62 & 29 & 150 & 196 & 28 & 159 \\
\hline 16 & 84 & 8 & 145 & 174 & 19 & 15 \\
\hline 17 & 65 & 45 & 223 & 13 & 62 & 63 \\
\hline 18 & 16 & 26 & 321 & 7 & 101 & 34 \\
\hline 19 & 27 & 71 & 96 & 63 & 186 & 50 \\
\hline 20 & 21 & 102 & 188 & 141 & 157 & 72 \\
\hline
\end{tabular}


Table 14. Optimal procurement of component 3 from suppliers for DE/Rand/1/bin

\begin{tabular}{ccccccc}
\hline Scenario & $\begin{array}{c}\text { Plant 1 } \\
\text { Supplier 1 }\end{array}$ & $\begin{array}{c}\text { Plant 1 } \\
\text { Supplier 2 }\end{array}$ & $\begin{array}{c}\text { Plant 1 } \\
\text { Supplier 3 }\end{array}$ & $\begin{array}{c}\text { Plant 2 } \\
\text { Supplier 1 }\end{array}$ & $\begin{array}{c}\text { Plant 2 } \\
\text { Supplier 2 }\end{array}$ & $\begin{array}{c}\text { Plant 2 } \\
\text { Supplier 3 }\end{array}$ \\
\hline $\mathbf{1}$ & 222 & 139 & 120 & 17 & 185 & 65 \\
$\mathbf{2}$ & 53 & 323 & 64 & 80 & 240 & 10 \\
$\mathbf{3}$ & 343 & 32 & 58 & 39 & 192 & 21 \\
$\mathbf{4}$ & 281 & 56 & 81 & 18 & 195 & 21 \\
$\mathbf{5}$ & 313 & 34 & 81 & 14 & 193 & 27 \\
$\mathbf{6}$ & 393 & 6 & 11 & 106 & 192 & 28 \\
$\mathbf{7}$ & 240 & 109 & 87 & 45 & 149 & 33 \\
$\mathbf{8}$ & 127 & 151 & 120 & 30 & 103 & 133 \\
$\mathbf{9}$ & 391 & 3 & 122 & 10 & 107 & 142 \\
$\mathbf{1 0}$ & 293 & 98 & 139 & 3 & 107 & 88 \\
$\mathbf{1 1}$ & 208 & 28 & 83 & 23 & 182 & 25 \\
$\mathbf{1 2}$ & 161 & 230 & 88 & 50 & 170 & 80 \\
$\mathbf{1 3}$ & 350 & 8 & 42 & 94 & 178 & 12 \\
$\mathbf{1 4}$ & 169 & 140 & 89 & 47 & 203 & 21 \\
$\mathbf{1 5}$ & 334 & 44 & 64 & 80 & 217 & 13 \\
$\mathbf{1 6}$ & 251 & 104 & 128 & 9 & 229 & 13 \\
$\mathbf{1 7}$ & 240 & 143 & 67 & 67 & 183 & 55 \\
$\mathbf{1 8}$ & 343 & 11 & 83 & 15 & 19 & 197 \\
$\mathbf{1 9}$ & 264 & 36 & 28 & 97 & 172 & 55 \\
$\mathbf{2 0}$ & 125 & 222 & 67 & 27 & 212 & 8 \\
\hline
\end{tabular}

\section{CONCLUSION}

During the past fifteen years, differential evolution (DE) which is an efficient and robust evolutionary algorithm has become a hot spot in the community of evolutionary computation. In this paper, the performance of five DE variants has been investigated by solving three stage multi-echelon supply chain network optimization problem for twenty demand scenarios with each supply chain settings. Five variants of DE are proposed to solve the three echelons SCN architecture and the results were compared with GA, PSO and optimal solutions reported by Cardenas et.al,[24]. Computational results demonstrate the efficiency of variant DE/Rand/1/bin to solve the SCN problem and superior performance over GA and PSO in all the problem instances. Future research can be interesting to build and solve a mathematical model for multiple states, multiple products with multi periods. Also, recent local search methods can be extended because of their potential to enhance the performance of the proposed solving approach to search the nearoptimal solution in the reasonable time.

\section{ACKNOWLEDGEMENT}

The authors would like to acknowledge the financial support from the University Malaysia Pahang through the research grant with the grant number RDU180374.

\section{REFERENCES}

[1] Kadadevaramath, R. S., Chen, J. C., Shankar, B. L., \& Rameshkumar, K. (2012). Application of particle swarm intelligence algorithms in supply chain network architecture optimization. Expert Systems with Applications, 39(11), 10160-10176

[2] Amiri, A. (2006). Designing a distribution network in a supply chain system: Formulation and efficient solution procedure. European journal of operational research, 171(2), 567-576.

[3] Feyzian-Tary, I., Razmi, J., \& Sangari, M. S. (2018). A variational inequality formulation for designing a multi-echelon, multi-product supply chain network in a competitive environment. Annals of Operations Research, 264(1-2), 89-121.

[4] Ebikake, E., Sassanelli, C., \& Terzi, S. (2018). PSS design through Design for Supply Chain: State of the art review.

[5] Clark, A. J., \& Scarf, H. (1960). Optimal policies for a multi-echelon inventory problem. Management science, 6(4), 475-490.

[6] Clark, A. J., \& Scarf, H. (1962). Approximate solutions to a simple multi-echelon inventory problem. Studies in applied probability and management science, 88-110. 
[7] Diks, E. B., De Kok, A. G., \& Lagodimos, A. G. (1996). Multi-echelon systems: A service measure perspective. European Journal of Operational Research, 95, 241-263.

[8] Tarhan, B., \& Grossmann, I. E. (2008). A multistage stochastic programming approach with strategies for uncertainty reduction in the synthesis of process networks with uncertain yields. Computers \& Chemical Engineering, 32 (4-5), 766-788.

[9] Morris, A. C., \& Sanqwon, M. (1990). Impact of production scale economies, manufacturing complexity, and transportation costs on supply chain facility networks (No. REP-12849. CIMMYT.).

[10] Cohen, M. A., \& Lee, H. L. (1989). Resource deployment analysis of global manufacturing and distribution networks. Journal of manufacturing and operations management, 2(2), 81-104.

[11] Sue-Ann, G., Ponnambalam, S. G., \& Jawahar, N. (2012). Evolutionary algorithms for optimal operating parameters of vendor managed inventory systems in a two-echelon supply chain. Advances in Engineering Software, 52, 47-54.

[12] Che, Z. H. (2012). A particle swarm optimization algorithm for solving unbalanced supply chain planning problems. Applied Soft Computing, 12(4), 1279-1287.

[13] Ishii, K., Takahashi, K., \& Muramatsu, R. (1988). Integrated production, inventory and distribution systems. The International Journal Of Production Research, 26(3), 473-482.

[14] Pyke, D. F., \& Cohen, M. A. (1990). Push and pull in manufacturing and distribution systems. Journal of Operations Management, 9(1), 24-43.

[15] Babu, B. V., \& Gujarathil, A. M. (2007, September). Multi-objective differential evolution (MODE) for optimization of supply chain planning and management. In Evolutionary Computation, 2007. CEC 2007. IEEE Congress on (pp. 2732-2739). IEEE.

[16] Cohen, M. A., \& Lee, H. L. (1989). Resource deployment analysis of global manufacturing and distribution networks. Journal of manufacturing and operations management, 2(2), 81-104.

[17] Tsiakis, P., Shah, N., \& Pantelides, C. C. (2001). Design of multi-echelon supply chain networks under demand uncertainty. Industrial \& Engineering Chemistry Research, 40(16), 3585-3604.

[18] Atamtürk, A., Berenguer, G., \& Shen, Z. J. (2012). A conic integer programming approach to stochastic joint location-inventory problems. Operations Research, 60(2), 366-381.

[19] Shahabi, M., Akbarinasaji, S., Unnikrishnan, A., \& James, R. (2013). Integrated inventory control and facility location decisions in a multi-echelon supply chain network with hubs. Networks and Spatial Economics, 13(4), 497-514.

[20] Storn, R., \& Price, K. (1997). Differential evolution-a simple and efficient heuristic for global optimization over continuous spaces. Journal of global optimization, 11(4), 341-359.

[21] Damak, N., Jarboui, B., Siarry, P., \& Loukil, T. (2009). Differential evolution for solving multi-mode resource-constrained project scheduling problems. Computers \& Operations Research, 36(9), 2653-2659.

[22] Doolun, I. S., Ponnambalam, S. G., Subramanian, N., \& Kanagaraj, G. (2018). Data driven hybrid evolutionary analytical approach for multi objective location allocation decisions: Automotive green supply chain empirical evidence. Computers \& Operations Research.

[23] Thoucharee, S., Pitakaso, R., \& Phannikul, T. (2017). Application of Modified Differential Evolution for the supply chain management of rice in the lower North-Eastern Region of Thailand. Songklanakarin Journal of Science \& Technology, 39(5).

[24] Cárdenas-Barrón, L. E., \& Treviño-Garza, G. (2014). An optimal solution to a three echelon supply chain network with multi-product and multi-period. Applied Mathematical Modelling, 38(5-6), 1911-1918. 